\section{Kidney \\ Blood Pressure Research}

Kidney Blood Press Res 2017;42:974-982

DOI: 10.1159/000485343

Published online: November 27, 2017

Accepted: July 22, 2017

This article is licensed under the This article is licensed under the Creative Commons Attribution-NonCommercial-NoDerivatives 4.0 International License (CC BY-NC-ND) (http.//Www.karger.com/Services/OpenAccessLicense). Usage and distribut

\title{
Maternal Hypercholesterolemia Associated with Nicotine Exposure in Adulthood May Induce Kidney Injury in Male Rats if Hypomagnesemia Occurs
}

\author{
Claudia M.B. Helou Rildo A. Volpini Mirela A.R. Santinho Fabricio L. Fonseca \\ André L. Simião
}

Laboratório de Pesquisa Básica (LIM-12), Nefrologia, Hospital das Clínicas da Faculdade de Medicina da Universidade de São Paulo, São Paulo/SP, Brazil

\section{Key Words}

Fetal programming - Hypercholesterolemia $\cdot$ Hypomagnesemia - Kidney injury • Nicotine • Renal function

\begin{abstract}
Background/Aims: Maternal hypercholesterolemia is a risk factor to renal injury in rat pups at adulthood, especially if they feed a cholesterol-enriched diet after weaning. However, the renal function of male pups of dams with hypercholesterolemia $(\mathrm{PH})$ that were fed a regular chow from weaning to adulthood needs investigation, particularly those exposed to an adverse risk such as nicotine. Methods: We evaluated the renal function of PH animals and we compared the data with those found in male pups of control dams (PC) at 3-and 6-month-old by inulin clearance. Moreover, we investigated the effect of nicotine treatment for 8 days in both $\mathrm{PH}$ and PC animals at 6 months old via metabolic function studies and by renal histological analysis. Results: Inulin clearance and other renal function parameters were similar in $\mathrm{PH}$ and PC animals at 3 and 6 months old. Nevertheless, the PH group showed significant differences with regard to histological analysis despite a similar number of glomeruli. The glomerular area of PH animals was significantly smaller than that measured in PC animals, and the fractional interstitial area was significantly larger in PH animals than that measured in PC animals at 3 months old. With regard to nicotine treatment, we observed a trend for a reduction in creatinine clearance in both PC and PH groups, but only PH animals showed hypomagnesemia and the highest fractional interstitial area. Conclusions: The offspring exposed to a high cholesterol milieu during intrauterine and neonatal life may show a silent kidney injury at adulthood that may be aggravated by nicotine exposure if hypomagnesemia occurs.
\end{abstract}




\section{Kidney Blood Pressure Research}

\section{Introduction}

Hypercholesterolemia can induce renal injury due to its direct action on vascular reactivity and by triggering oxidative stress and inflammation in non-vascular tissue [1-3].

In previous studies, we evaluated the renal function of rats fed a cholesterol-enriched diet for one week [4-6]. Although cholesterol levels have doubled in the serum, the glomerular filtration rate and blood pressure values have remained within normal range. However, hypercholesterolemic rats developed renal tubular dysfunction manifested by magnesuria owing to a reduction in the expression of the epithelial $\mathrm{Mg}^{2+}$ channel (TRPM6) in the renal cortex [5]. In addition, hypercholesterolemic rats treated with rosiglitazone showed renal injury [6], whereas hypercholesterolemic rats treated with nicotine have demonstrated evidence of impairment in their renal autoregulation [4]. Therefore, we may hypothesize that hypercholesterolemia acted as a 'first hit' to renal dysfunction resulting in magnesium deficiency and that the treatment with rosiglitazone or nicotine may provoke a 'second hit', allowing the development of renal injury. This hypothesis is in agreement with the literature that reports that a 'single hit' may not be enough to induce renal dysfunction [7].

Many experimental and human studies have linked environmental and maternal influences during fetal and perinatal life to cardiorenal diseases in adulthood [8-18]. As preterm births often occur in these cases, a recent study using metabolomics profile identified a biomarker in the blood of pregnant women predicting who might be in risk group [18]. Previously, we have also evaluated the influence of maternal hypercholesterolemia in rat offspring. We found low body weight at birth correlates with high mortality at birth and during neonatal life. Additionally, the pups exposed to maternal hypercholesterolemia and fed a cholesterol-enriched diet after weaning had a reduction in their renal function at 3 months old [15]. However, the effects in the renal function of offspring exposed to maternal hypercholesterolemia that were fed regular rat chow from weaning to adulthood are not clear yet.

Hence, we propose to evaluate whether maternal hypercholesterolemia may act as a 'first hit' to cause offspring renal dysfunction at adulthood, even if they were fed a regular rat chow after weaning. We also propose to investigate whether another risk factor to cardiovascular disease can act as a 'second hit' to renal dysfunction at adult life. Thus, we chose to treat the sibling male rats exposed to a high cholesterol milieu during intrauterine and neonatal life with nicotine at 6 months old.

\section{Materials and Methods}

The Research Ethics Committee of our institution (Comissão de Ética para Análise de Projetos de Pesquisa - CAPPesq, da Diretoria Clínica do Hospital das Clínicas da Faculdade de Medicina da Universidade de São Paulo) approved this study, and we conducted all experiments according to the National Research Council Guide for the Care and Use of Laboratory Animals. Animals had free access to food and water throughout the study, and we anesthetized them for all surgical preparations with sodium thiopental (50 mg/kg b.w. i.p.).

\section{Study design}

We randomly housed 28 female Wistar rats weighing 180-220 g, obtained from the Animal Center of our institution, in individual cages one week prior to mating in our laboratory. Half of them were fed a standard diet (control dams) and the other half were fed an enriched-cholesterol diet (hypercholesterolemic dams) in the same protocol that we have previously reported [15]. In the present study, we fed both male pups of control (PC) and hypercholesterolemic (PH) dams with regular rat chow throughout the study after weaning. 


\section{Kidney Blood Pressure Research}

Helou et al.: Maternal Hypercholesterolemia and Kidney Injury in their Offsprings

\section{Renal function study}

We evaluated the renal function of both PC and PH groups at 3 and 6 months old by measuring inulin clearance as previously described $[4,6]$.

Briefly, we placed catheters in the trachea, jugular veins, carotid artery and bladder. Thereafter, we intravenously administered a priming dose of inulin (100 mg/kg b.w. diluted in $0.9 \%$ saline) followed by a sustained inulin infusion (10 mg/kg b.w.) at a rate of $0.04 \mathrm{ml} / \mathrm{min}$. Prior to the start of the experiment a stabilization period of at least 30 minutes was allowed, before two urine samples were each collected at 30-min intervals. Moreover, we also collected blood samples at the beginning and at the end of the experiment. In all urine and blood samples, we measured inulin by the anthrone assay and $\mathrm{Na}^{+}$and $\mathrm{K}^{+}$by flame photometry (CELM-FC280). We also measured mean blood pressure (BP) at the beginning and at the end of the experiment by a catheter placed in the carotid artery, and we expressed the average values in $\mathrm{mm}$ $\mathrm{Hg}$.

\section{Nicotine exposure}

In another set of PC and PH animals at 6 months old, we separated the sibling animals to treat them with or without $12.5 \mu \mathrm{g} / \mathrm{ml}$ nicotine (Sigma Chemical, St. Louis, MO, USA) in drinking water ad libitum. On the eighth day of treatment, we placed the animals in individual metabolic cages to collect urine under oil. After a 24h-period, we anesthetized the animals to catheterize the abdominal aorta to measure BP and to collect blood samples.

We quantified creatinine, magnesium $\left(\mathrm{Mg}^{2+}\right)$, phosphorous $(\mathrm{P})$ and chloride $(\mathrm{Cl})$ in urine and blood samples by colorimetric methods. We also measured total cholesterol in the serum and the protein in the urine by using test kits (Labtest; Minas Gerais, Brazil).

\section{Renal histological study}

After blood collection, we removed and fixed the kidneys of both PC and PH animals at 3 and 6 months old in 4\% paraformaldehyde, post-fixed in Bouin's solution and processed for paraffin embedding. The renal tissues were sliced into $4 \mu \mathrm{m}$ and stained with either hematoxylin and eosin or Masson's trichrome for histological examination under light microscopy. We measured the fractional interstitial area (FIA) of the renal cortex and the glomerular area stained with Masson's trichrome by the morphometry method using a light camera connected to an image analyzer (Axiovision, Carl Zeiss, Eching, Germany) [19]. We counted the number of glomeruli in each section as a whole and evaluated the glomerular area by encircling the outer edges of the glomeruli tufts in 50 sequential grid fields measuring $0.087 \mathrm{~mm}^{2}$. For evaluation of FIA, we analyzed 20 sequential grid fields also measuring $0.087 \mathrm{~mm}^{2}$ in the renal cortex of each kidney section. The interstitial areas were demarcated manually on a video screen, and the proportion of the outlined field was determined by computerized morphometry [20]. We used 50 grid fields to evaluate the glomerular area because this study is usually clean to be executed, that is, there is no interference of technical artifacts. On the contrary, when evaluating the FIA, it is necessary to avoid fractured areas, large vessels, presence of the glomeruli, and edges and corners of the field as well, which contribute to the exclusion of some grid fields.

\section{Statistical analysis}

We expressed data as mean \pm SE. We used paired Student's t-test to compare data of the same animal and unpaired Student's t-test to compare data of histological study at 3 months old. We also used the analysis of variance (ANOVA) and the Tukey's post hoc test for comparisons between groups and the Dunnett's post hoc test for comparisons with PC rats treated with water (control group). GraphPad Prism 5.0 (La Jolla, CA) was used for statistical analyses and statistical significance was set at $\mathrm{P} \leq 0.05$.

\section{Results}

\section{Evaluation at 3 months old}

Both PC and $\mathrm{PH}$ rats exhibited a normal range in body weight, blood pressure, renal function parameters and electrolyte homeostasis at 3 months old (Table 1). However, both $\mathrm{PC}$ and $\mathrm{PH}$ rats showed significant differences with regard to histological analysis despite 


\section{Kidney Blood Pressure Research}

a similar number of glomeruli (Fig. 1A). The glomerular area of $\mathrm{PH}$ rats was significantly smaller than that measured in the PC group (Fig. 1B), and the FIA of the $\mathrm{PH}$ group was significantly larger than that found in the PC group (Fig. 1C). As illustrated in Fig. 1D, fibrosis is evident by the enlarged interstitial area in a representative photomicrograph of the $\mathrm{PH}$ group.

\section{Evaluation at 6 months old}

Both PC and PH animals at 6 months old showed higher body weight than at 3 months old, which naturally occurs during the animal's growth. Again, blood pressure, renal function parameters and electrolyte homeostasis were within normal range values in both $\mathrm{PC}$ and $\mathrm{PH}$ rats at 6 months old (Table 1).

With regard to the renal histological study, the glomerular area did not differ in PC animals at 3 and 6 months old (Fig. 2A). However, the glomerular area in the 6-month-old $\mathrm{PH}$ group was significantly higher than 3-month-old $\mathrm{PH}$ animals $(\mathrm{P}<0.01$; Fig. 2 A). As illustrated in Fig. 2B, the FIA was significantly higher in PC and PH animals at 6 months old than that measured in the PC group at 3 months old. We did not detect any difference in the FIA in both 3- and 6-month-old PH animals.

Fig. 1. Renal histological analysis in male pups of control (PC) and hypercholesterolemic $(\mathrm{PH})$ dams at 3 months old. A: Glomeruli number count is similar in both $\mathrm{PC}$ and $\mathrm{PH}$ groups. B: Glomerular area is smaller in $\mathrm{PH}$ than in PC group. C: FIA is larger in $\mathrm{PH}$ than in $\mathrm{PC}$ group. D: Representative photomicrographs of cortical kidney sections of PC and PH groups stained with hematoxylin and eosin, x400 magnification. Fibrosis is seen clearly in enlarged interstitial area of the PH group (arrows). Columns and error bars represent mean \pm standard error ${ }^{*} \mathrm{P}<0.05$ for $\mathrm{PH}$ vs. PC, derived from Student's unpaired t-test.
Table 1. Renal function studies in male pups of control and hypercholesterolemic dams at 3 and 6 months old. Data are expressed as mean \pm SE. PC: pups whose dams fed a standard diet; PH: pups whose dams fed a cholesterolenriched diet; ${ }^{*} \mathrm{P}<0.01$ vs. $\mathrm{PH}$ at 3 months old derived from analysis of variance followed by Tukey's test

\begin{tabular}{lcccc}
\hline & \multicolumn{2}{c}{3 months old } & \multicolumn{2}{c}{6 months old } \\
& $\mathrm{PC}(\mathrm{n}=4)$ & $\mathrm{PH}(\mathrm{n}=7)$ & $\mathrm{PC}(\mathrm{n}=8)$ & $\mathrm{PH}(\mathrm{n}=6)$ \\
\hline Body weight $(\mathrm{g})$ & $308 \pm 35$ & $366 \pm 12$ & $436 \pm 16^{*}$ & $443 \pm 27^{*}$ \\
Blood pressure $(\mathrm{mmHg})$ & $118 \pm 4$ & $114 \pm 2$ & $122 \pm 2$ & $119 \pm 4$ \\
& & & & \\
Inulin clearance $(\mathrm{ml} / \mathrm{min} / 100 \mathrm{~g})$ & $0.88 \pm 0.06$ & $0.73 \pm 0.10$ & $0.90 \pm 0.10$ & $0.73 \pm 0.12$ \\
Plasma Na+ $(\mathrm{mmol} / \mathrm{l})$ & $138 \pm 3$ & $133 \pm 2$ & $133 \pm 4$ & $138 \pm 2$ \\
Plasma $\mathrm{K}^{+}(\mathrm{mmol} / \mathrm{l})$ & $5.32 \pm 0.27$ & $4.49 \pm 0.34$ & $3.96 \pm 0.30$ & $3.82 \pm 0.38$ \\
& $14.1 \pm 4.5$ & $10.5 \pm 2.5$ & $8.0 \pm 1.2$ & $13.1 \pm 3.9$ \\
Urine output $(\mu \mathrm{l} / \mathrm{min})$ & $1.71 \pm 0.87$ & $1.07 \pm 0.54$ & $0.84 \pm 0.30$ & $1.79 \pm 0.74$ \\
$\mathrm{Na}^{+}$excretion $(\mu \mathrm{mol} / \mathrm{min})$ & $1.70 \pm 0.19$ & $2.49 \pm 0.82$ & $1.68 \pm 0.44$ & $2.02 \pm 0.61$ \\
$\mathrm{~K}^{+}$excretion $(\mu \mathrm{mol} / \mathrm{min})$ & & & & \\
\end{tabular}

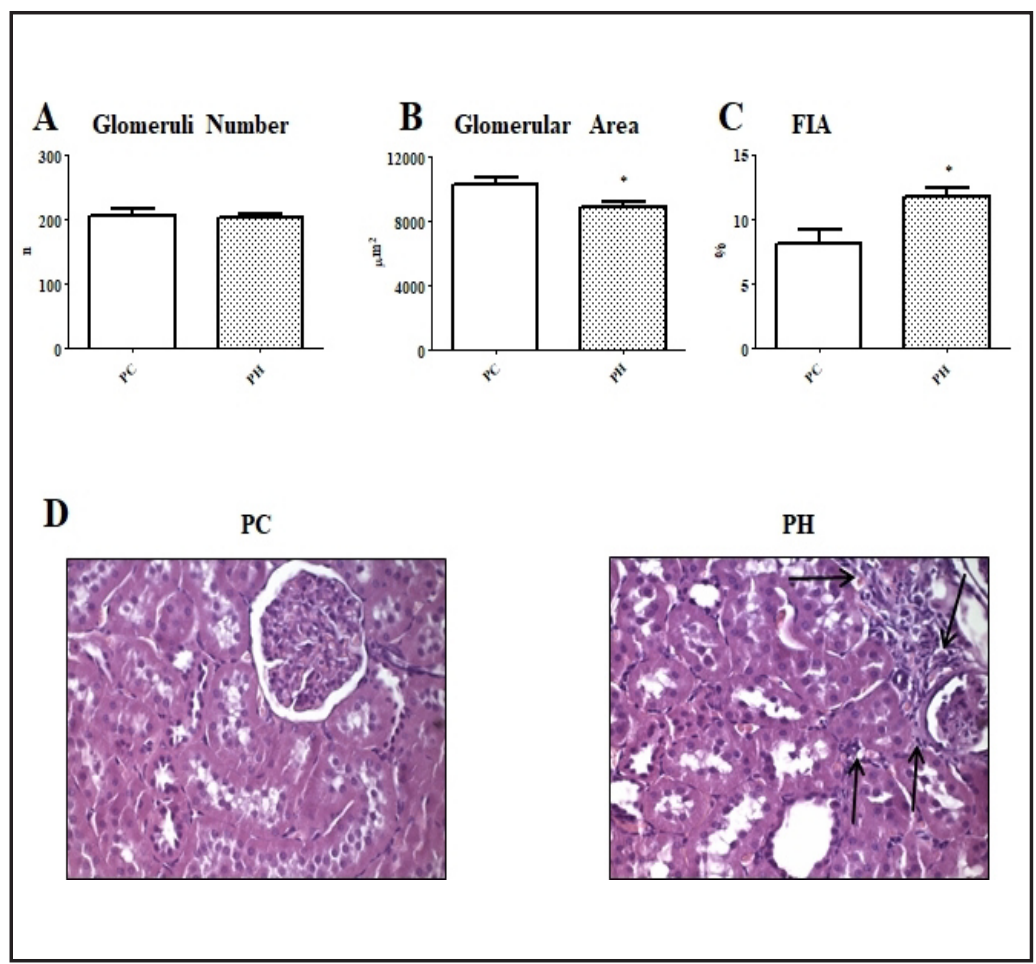




\section{Kidney Blood Pressure Research}

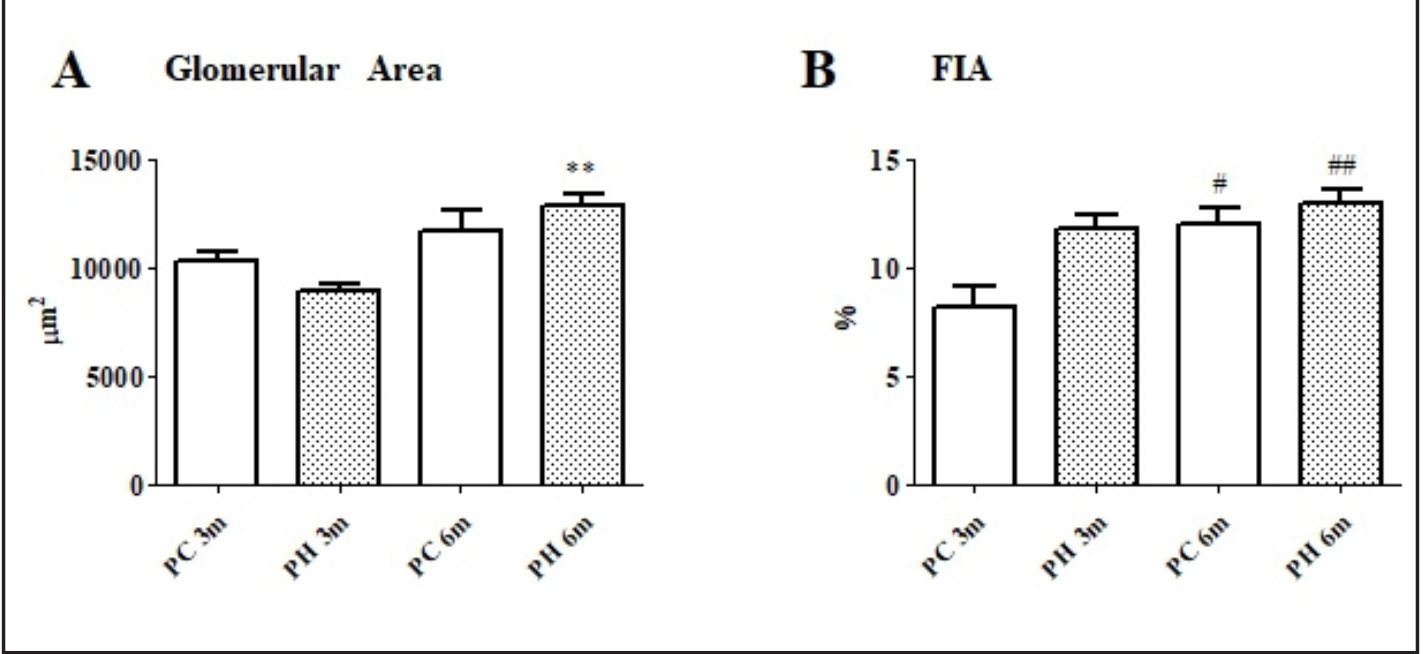

Fig. 2. Renal histological analysis in male pups of control (PC) and hypercholesterolemic (PH) dams at 3 and 6 months old. A: Glomerular area is similar in both 3- and 6-month-old PC animals, and it is significantly higher in 6- month-old PH animals than in 3-month-old PH animals. B: FIA is significantly higher in both PC and PH animals at 6 months old than that measured in the PC group at 3 months old; and we did not detect any difference in the FIA in both groups of PH animals at 3 and 6 months old. Columns and error bars represent mean \pm standard error. ${ }^{* *} \mathrm{P}<0.01$ vs. $\mathrm{PH}$ animals at 3 months old derived from ANOVA followed by Tukey's test. ${ }^{\#} \mathrm{P}<0.05$ and ${ }^{\# \#} \mathrm{P}<0.01$ vs. $\mathrm{PC}$ animals at 3 months old, derived from ANOVA followed by Tukey's test.

\section{Nicotine exposure}

Sibling PC rats treated with or without nicotine showed similar body weight, food intake and drinking intake during the treatment (Table 2). However, $\mathrm{PH}$ rats treated with water ate less quantities of food than PC rats treated with water. In addition, we observed a significant reduction in body weight of the sibling PH rats treated with or without nicotine (Table 2).

The nicotine treated groups had a tendency for lower creatinine clearance than their water-treated counterparts. Moreover, the treatment with nicotine did not induce any abnormality with regard to electrolyte homeostasis, except for the serum magnesium levels. Both PC and PH rats treated with nicotine showed hypomagnesemia, but they had levels of magnesium urinary excretion in the same range as the untreated sibling group (Table 2).

With regard to the renal histological study, we found similar glomerular area in both PC and $\mathrm{PH}$ rats treated with or without nicotine (Fig. 3A). Yet, we observed the largest FIA in PH animals treated with nicotine (Fig. 3B-F).

\section{Discussion}

Our data suggest that maternal hypercholesterolemia may predispose male adult rats to kidney injury even if they were fed regular chow after weaning. Renal injury, demonstrated by an increase in the FIA, became more evident when we exposed the animals to nicotine at 6 months old. Both PC and PH nicotine-treated animals developed hypomagnesemia due to extra-renal mechanisms. Nevertheless, we found larger zones of FIA only in PH nicotinetreated animals. Taken together, these findings suggest that maternal hypercholesterolemia may act as a 'first hit' to renal injury, and nicotine exposure associated with hypomagnesemia may trigger the 'second hit' in renal injury progression.

Fetal and neonatal exposure to adverse factors may induce changes in renal structure. Many studies describe that a reduction in nephron number may predispose to the development 


\section{Kidney Blood Pressure Research}

of hypertension and susceptibility to renal injury in adulthood [10, 21]. In the present study, we found similar nephron number in both PH and PC animals. Nonetheless, we found a reduction in glomerular area and an increment in the FIA in the histological study of $\mathrm{PH}$ groups at 3 months old. These findings may indicate a 'silent' kidney injury because the animals did not show any abnormalities in their values of blood pressure, glomerular filtration rate and electrolyte homeostasis. Thus, these findings supported our proposition to investigate whether nicotine exposure in adult life may play a role in the progression of renal injury in offspring exposed to maternal hypercholesterolemia.

When we evaluated $\mathrm{PC}$ and $\mathrm{PH}$ groups treated with or without nicotine at 6 months old in metabolic cages, we observed a trend for a reduction in creatinine clearance in both PC and PH rats treated with nicotine. Creatinine clearance has some limitations as a measure of glomerular filtration rate (GFR) as rats have low amounts of muscle mass [22]. Moreover, the metabolic cage method requires a long period to collect the urine and imprecisions in urine output determinations may occur, consequently. Thus, creatinine clearance data usually present low values, which might decrease the possibility to detect significant differences in statistical analysis. In our previous study, we observed a significant reduction in GFR exerted by nicotine considering that we used the technique of inulin clearance [4]. This method shows fewer errors in accuracy and precision thus allowing many investigators to indicate inulin clearance as the gold standard method to measure GFR [23]. We did not choose inulin clearance measurement to evaluate GFR in PC and PH animals treated with nicotine because we did not have enough sibling male pups that reached the age of 6 months old to apply this method.

Nicotine may also exacerbate oxidative stress associated or not with increases in extracellular matrix and inflammation [24-26]. Oxidative stress may lead to magnesium deficiency that also increases the inflammatory response and plays a role in degenerative and chronic diseases [27-29]. Therefore, both oxidative stress and magnesium deficiency are the cause and effect of each other to increase the inflammation and fibrosis process in many organs, as for example brain, heart and kidneys.

We have previously shown in hypercholesterolemic rats treated with rosiglitazone that renal injury was likely due to hypomagnesemia [6]. Furthermore, we also demonstrated renal

Table 2. Characteristics of sibling male pups of control and nicotine, Data are expressed as mean \pm SE. PC: pups whose dams fed a standard diet; PH: pups whose dams fed a cholesterol-enriched by Tukey's test and ${ }^{\circledR} \mathrm{P}<0.05$ vs control group (PC treated with water) derived from ANOVA followed by Dunnett's test and ${ }^{\#} \mathrm{P}<0.05$ vs. their initial body weight, derived from Student's paired t-test

\begin{tabular}{|c|c|c|c|c|}
\hline & \multicolumn{2}{|c|}{ PC } & \multicolumn{2}{|c|}{$\mathrm{PH}$} \\
\hline & Water & Nicotine & Water & Nicotine \\
\hline Number of animals & 7 & 7 & 8 & 8 \\
\hline Initial body weight (g) & $488 \pm 23$ & $485 \pm 22$ & $468 \pm 25$ & $463 \pm 15$ \\
\hline Final body weight (g) & $495 \pm 20$ & $479 \pm 22$ & $452 \pm 21^{\#}$ & $448 \pm 12^{\#}$ \\
\hline Body weight variation (g) & $7.1 \pm 12.3$ & $-5.7 \pm 4.7$ & $-16.2 \pm 7.0$ & $-15.6 \pm 6.4$ \\
\hline Average food intake (g/day) & $28.2 \pm 1.3$ & $25.4 \pm 0.7$ & $21.6 \pm 1.8^{*} \&$ & $26.8 \pm 1.4$ \\
\hline Average drink intake (ml/day) & $32.4 \pm 2.4$ & $30.0 \pm 1.6$ & $28.0 \pm 2.2$ & $27.8 \pm 2.9$ \\
\hline Drink intake in metabolic cage (ml) & $13.9 \pm 2.1$ & $7.6 \pm 2.1$ & $17.5 \pm 3.7$ & $8.6 \pm 2.2$ \\
\hline Urine output in metabolic cage (ml) & $14.2 \pm 2.2$ & $9.2 \pm 1.5$ & $17.3 \pm 2.6$ & $10.2 \pm 2.1$ \\
\hline Total cholesterol (mmol/l) & $1.74 \pm 0.23$ & $1.49 \pm 0.16$ & $1.16 \pm 0.19$ & $1.22 \pm 0.16$ \\
\hline Blood pressure (mm Hg) & $111 \pm 4$ & $113 \pm 6$ & $102 \pm 7$ & $112 \pm 4$ \\
\hline Creatinine clearance $(\mathrm{ml} / \mathrm{min} / 100 \mathrm{~g})$ & $0.39 \pm 0.03$ & $0.32 \pm 0.02$ & $0.38 \pm 0.05$ & $0.32 \pm 0.03$ \\
\hline Proteinuria/creatinine & $0.85 \pm 0.10$ & $0.72 \pm 0.08$ & $0.70 \pm 0.10$ & $0.65 \pm 0.08$ \\
\hline Plasma $\mathrm{Na}^{+}(\mathrm{mmol} / \mathrm{l})$ & $143 \pm 3$ & $141 \pm 3$ & $142 \pm 3$ & $140 \pm 2$ \\
\hline $\mathrm{Na}^{+}$excretion $(\mu \mathrm{mol} /$ day $)$ & $368 \pm 59$ & $348 \pm 81$ & $434 \pm 94$ & $378 \pm 40$ \\
\hline Plasma K+ $(\mathrm{mmol} / \mathrm{l})$ & $3.80 \pm 0.20$ & $3.46 \pm 0.19$ & $3.96 \pm 0.41$ & $3.44 \pm 0.28$ \\
\hline $\mathrm{K}^{+}$excretion $(\mu \mathrm{mol} /$ day $)$ & $1978 \pm 207$ & $1694 \pm 97$ & $1521 \pm 188$ & $1876 \pm 218$ \\
\hline Plasma Cl- $(\mathrm{mmol} / \mathrm{l})$ & $115 \pm 8$ & $112 \pm 6$ & $113 \pm 7$ & $109 \pm 5$ \\
\hline $\mathrm{Cl}^{-}$excretion $(\mu \mathrm{mol} /$ day $)$ & $331 \pm 98$ & $465 \pm 87$ & $486 \pm 136$ & $713 \pm 274$ \\
\hline Plasma $\mathrm{Mg}^{2+}(\mathrm{mmol} / \mathrm{l})$ & $0.84 \pm 0.04$ & $0.68 \pm 0.08$ & $0.80 \pm 0.05$ & $0.65 \pm 0.03 \&$ \\
\hline $\mathrm{Mg}^{2+}$ excretion ( $\mu \mathrm{mol} /$ day) & $58 \pm 11$ & $56 \pm 15$ & $49 \pm 7$ & $42 \pm 10$ \\
\hline Plasma Pi (mmol/l) & $1.74 \pm 0.28$ & $1.76 \pm 0.19$ & $1.74 \pm 0.15$ & $1.82 \pm 0.16$ \\
\hline Pi excretion $(\mu \mathrm{mol} /$ day $)$ & $371 \pm 70$ & $261 \pm 59$ & $329 \pm 65$ & $365 \pm 61$ \\
\hline
\end{tabular}




\section{Kidney Blood Pressure Research}

Fig. 3. Renal histological analysis in male pups of control (PC) and hypercholesterolemic $(\mathrm{PH})$ dams at 6 months old treated with water $(\mathrm{w})$ or nicotine (ni). A: Glomerular area is similar in both PC and $\mathrm{PH}$ animals treated with or without nicotine. B: FIA is significantly higher in $\mathrm{PH}$ rats treated with nicotine than other groups. Columns and error bars represent mean \pm standard error C-F: Representative photomicrographs

cortical kidney sections of PC and PH stained with hematoxylin and eosin, x400 magnification. The arrows show the enlarged interstitial area in $\mathrm{PH}$ rats treated with nicotine. * $\mathrm{P}<0.05$ for $\mathrm{PH}$ animals treated with nicotine vs. other groups, derived from analysis of variance followed by Tukey's test.
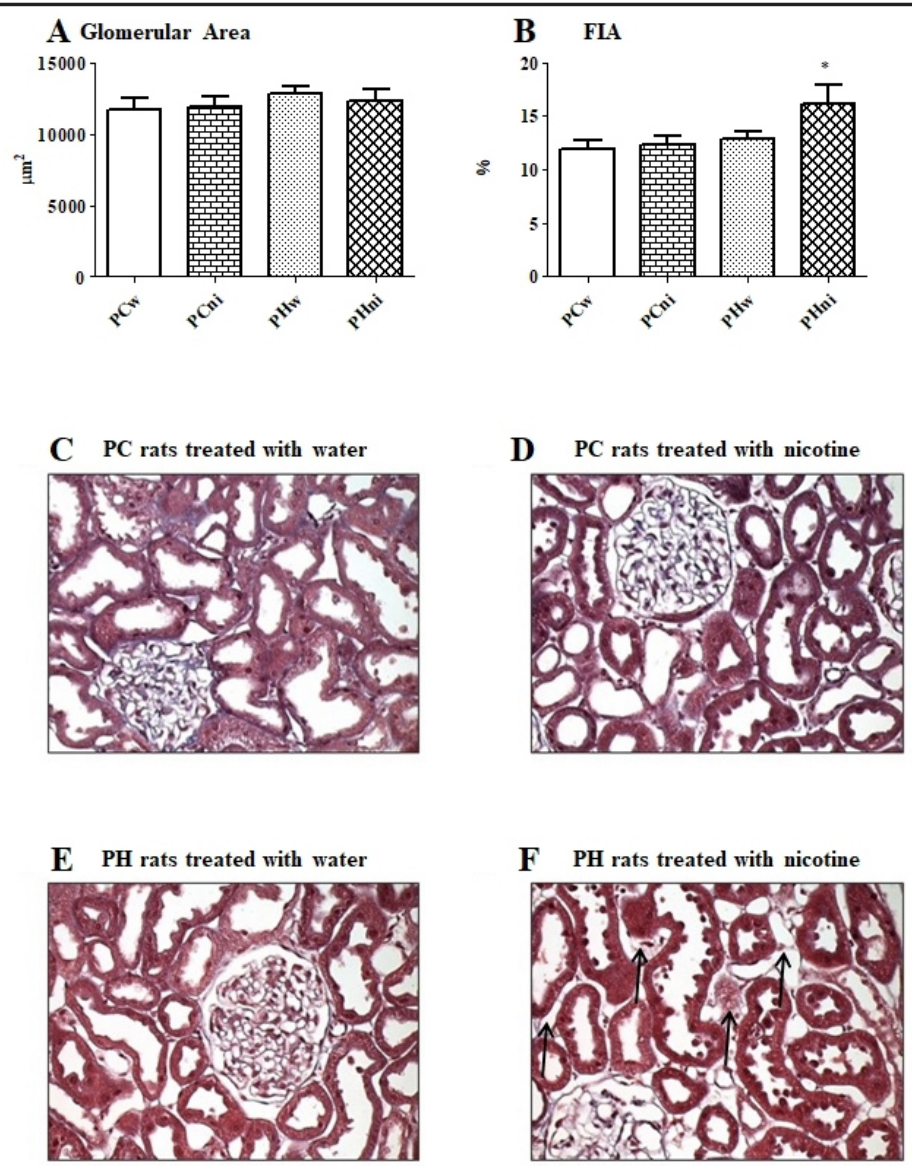

tubular dysfunction in hypercholesterolemic rats in another study [5]. Hypercholesterolemic rats developed hypomagnesemia due to magnesium urinary losses as a result of a reduction in expression of epithelial $\mathrm{Mg}^{2+}$ channels in the renal cortex (TRPM6) [5]. Hence, hypercholesterolemia, oxidative stress and hypomagnesemia are involved in a vicious cycle in which each one of them is the cause and the effect of the other.

In the present study, all animals showed total cholesterol serum levels within the normal range, and we found hypomagnesemia only in animals treated with nicotine. Both PC and PH rats treated with nicotine had similar magnesium urinary excretion rates, which may indicate an adverse effect exerted by nicotine in the gastrointestinal tract [30].

In the small intestine, large amounts of magnesium absorption occur paracellulary, whereas fine-tuning of magnesium absorption occurs in the cecum and colon by transcellular transport [29, 31]. In the distal intestine, TRPM6 channels are expressed [32]. In fact, TRPM6 interacts with a homolog protein called TRPM7 resulting in a TRPM6/7 complex that regulates the $\mathrm{Mg}^{2+}$ entry in intestinal cells [33]. Ryazanova et al. demonstrated the importance of TRPM7 in regulating magnesium homeostasis especially by their alpha-kinase domain. They suggested that TRPM7 kinase is involved in cell death caused by oxidative stress [34]. Thus, further studies addressing TRPM6 and TRPM7 in the gastrointestinal tract might help to elucidate the effect of nicotine in digestive system cells.

Lastly, we would like to emphasize that our study design cautiously considered evaluating only one pup per mother in each group. This criterion differs from some studies in the literature that include two or three pups in the same groups to receive the same kind of treatment. In these studies, an important bias occurs because the findings may show only an epiphenomenon. In summary, our study is really significant as it is in agreement with the foetal programming hypothesis. $\mathrm{PH}$ animals showed a silent renal injury at 3 months old that progresses after another trigger effect. 


\section{Kidney \\ Blood Pressure Research}

\section{Conclusion}

A high cholesterol milieu during intrauterine and neonatal life may act as a 'first hit' to a silent kidney injury, and nicotine exposure associated with hypomagnesemia may trigger the 'second hit' in the progression of renal injury.

\section{Disclosure Statement}

None.

\section{Acknowledgements}

Laboratório de Investigação Médica - HCFMUSP, Fundação Faculdade Medicina (FFM) and Fundação de Amparo à Pesquisa do Estado de São Paulo (FAPESP - Grant no 2010/522940 ) supported this study. André L. Simião received a grant of FAPESP no 2004/02449-6. The authors thank Fabiola M. Oshiro-Monreal for her technical assistance.

\section{References}

1 Hansson GK, Robertson AKL, Söderberg-Nauclér C: Inflammation and atherosclerosis. Annu Rev Pathol Mech Dis 2006;1:297-329.

2 Wilensky RL, Macphee CH: Lipoprotein-associated phospholipase $\mathrm{A}_{2}$ and atherosclerosis. Curr Opin Lipidol 2009;20:415-420.

3 Chade AR, Lerman A, Lerman LO: Kidney in early atherosclerosis. Hypertension 2005;45:1042-1049.

4 Tamaoki L, Oshiro-Monreal F, Helou CMB: Effects of nicotine exposure on renal function of normal and hypercholesterolemic rats. Am J Nephrol 2009;30:377-382.

5 Favaro VF, Oshiro-Monreal FM, Bragança AC, Andrade L, Seguro AC, Helou CMB: High cholesterol feeding may induce tubular dysfunction resulting in hypomagnesemia. Kidney Blood Press Res 2012;35:137-146.

6 Dias C, Volpini RA, Helou CMB: Rosiglitazone did not induce acute kidney injury in normocholesterolemic rats despite reduction in glomerular filtration rate. Kidney Blood Press Res 2013;38:186-195.

7 Nenov VD, Taal MW, Sakharova OV, Brenner BM: Multi-hit nature of chronic renal disease. Curr Opin Nephrol Hypertens 2000;9:85-97.

-8 Barker DJ, Winter PD, Osmond C, Margetts B, Simmonds SJ: Weight in infancy and death from ischaemic heart disease. Lancet 1989;334:577-580.

-9 Ingelfinger JR, Woods LL: Perinatal programming, renal development, and adult renal function. Am J Hypertension 2002;15:46S-49S.

10 Kett MM, Denton KM: Renal programming: Cause for concern? Am J Physiol Regul Integr Comp Physiol 2011;300:R791-R803.

11 Palinski W: Sodium exposure induces stroke in a genetically susceptible model. New insights into early-life factors modulating adult disease. Circulation 2009;119:1459-1462.

12 Swanson JM, Entringer S, Buss C, Wadhwa PD: Developmental origins of health and disease: environmental exposures. Semin Reprod Med 2009;27:391-402.

13 Napoli C, Glass CK, Witztum JL, Deutsch R, D’Armiento FP, Palinski W: Influence of maternal hypercholesterolaemia during pregnancy on progression of early atherosclerotic lesions in childhood: fate of early lesions in children (FELIC) study. Lancet 1999;354:1234-1241.

14 Mudd LM, Holzman CB, Evans RW: Maternal mid-pregnancy lipids at birthweight. Acta Obstet Gynecol Scand 2015;94:852-860. 


\section{Kidney \\ Blood Pressure Research}

\begin{tabular}{l}
\hline Kidney Blood Press Res 2017;42:974-982 \\
\hline \begin{tabular}{l|l} 
DOI: 10.1159/000485343 & @ 2017 The Author(s). Published by S. Karger AG, Basel \\
Published online: November 27, 2017 & www.karger.com/kbr
\end{tabular} \\
\hline
\end{tabular}

Helou et al.: Maternal Hypercholesterolemia and Kidney Injury in their Offsprings

15 De Assis SM, Seguro AC, Helou CM: Effects of maternal hypercholesterolemia on pregnancy and development of offspring. Pediatr Nephrol 2003;18:328-334.

16 Slabiak-Blaz N, Adamczak M, Gut N, Grajoszek A, Nyengaard JR, Ritz E, Wiecek A: Administration of cyclosporine A in pregnant rats - the effect on blood pressure and on the glomerular number in their offspring. Kidney Blood Press Res 2015;40:413-423.

17 He X, Xie Z, Dong Q, Li J, Li W, Chen P: Effect of folic acid supplementation on renal phenotype and epigenotype in early weanling intrauterine growth retarded rats. Kidney Blood Press Res 2015;40:395-402.

18 Li J, Lu YP, Reichetzeder C, Kalk P, Kleuser B, Adamski J, Hocher B: Maternal PCaaC38:6 is associated with preterm birth - a risk factor for early and late adverse outcome of the offspring. Kidney Blood Press Res 2016;41:250-257.

19 Volpini RA, da Silva CG, Costa RS, Coimbra TM: Effect of enalapril and losartan on the events that precede diabetic nephropathy in rats. Diabetes Metab Res Rev 2003;19:43-51.

-20 Gonçalves JG, de Bragança AC, Canale D, Shimizu MH, Sanches TR, Moyses RM, Andrade L, Seguro AC, Volpini RA: Vitamin D deficiency aggravates chronic kidney disease progression after ischemic acute kidney injury. PLoS One 2014;9:e107228.

21 Brenner BM, Garcia DL, Anderson S: Glomeruli and blood pressure. Less of one, more the other? Am J Hypertens 1988;1:335-347.

22 Van Liew JB, Zamlauski-Tucker MJ, Feld LG: Endogenous creatinine clearance in the rat: strain variation. Life Sci 1993;53:1015-1021.

-23 Stevens LA, Levey AS: Measured GFR as a confirmatory test for estimated GFR. J Am Soc Nephrol 2009;20:2305-2313.

24 Arany I, Clark J, Reed DK, Juncos LA: Chronic nicotine exposure augments renal oxidative stress and injury through transcriptional activation of p66shc. Nephrol Dial Transplant 2013;28:1417-1425.

-25 Budisavljevic MN, Ploth DW: Nicotine and kidney: Mr. Hyde, and perhaps some Dr. Jekyll. Am J Physiol 2012;302:F1082-F1083.

-26 Singh VP, Singh N, Jaggi AS: A review on renal toxicity profile of common abusive drugs. Korean J Physiol Pharmacol 2013;17:347-357.

-27 Kolisek M, Montezano AC, Sponder G, Anagnostopoulou A, Vormann J, Touyz RM, Aschenbach JR: PARK7/ DJ-1 dysregulation by oxidative stress leads to magnesium deficiency: implications in degenerative and chronic diseases. Clin Sci 2015;129:1143-1150.

28 Malpuech-Brugère C, Nowacki W, Daveau M, Gueux E, Linard C, Rock E, Lebreton JP, Mazur A, Rayssiguier Y: Inflammatory response following acute magnesium deficiency in the rat. Biochim Biophys Acta 2000;1501:91-98.

29 Baaij JHF, Hoenderop JGJ, Bindels RJM: Magnesium in man: implications for health and disease. Physiol Rev 2015;95:1-46.

-30 Chu KM, Cho CH, Shin VY: Nicotine and gastrointestinal disorders: its role in ulceration and cancer development. Curr Pharm Des 2013;19:5-10.

-31 Quamme GA: Recent developments in intestinal magnesium absorption. Curr Opin Gastroenterol 2008;24:230-235.

-32 Lameris AL, Nevalainen PI, Reijnen D, Simons E, Eygensteyn J, Monnens L, Bindels RJM, Hoenderop JGJ: Segmental transport of $\mathrm{Ca}^{2+}$ and $\mathrm{Mg}^{2+}$ along the gastrointestinal tract. Am J Physiol 2015;308:G206-G216.

-33 Schlingmann KP, Waldegger S, Konrad M, Chubanov V, Gudermann T: TRPM6 and TRPM7 - gatekeepers of human magnesium metabolism. Biochim Biophys Acta 2007;1772:813-821.

-34 Ryazanova LV, Hu Z, Suzuki S, Chubanov V, Fleig A, Ryazanov AG: Elucidating the role of the TRPM7 alphakinase: TRPM7 kinase inactivation leads to magnesium deprivation resistance phenotype in mice. Sci Rep 2014;4:7599:1-11. 